\title{
Gastrinoma of Cystic Duct: A Rare Association With Multiple Endocrine Neoplasia Type 1
}

\author{
Aline Barbosa Moraes ${ }^{\mathrm{a}}$, Natalia Treistman ${ }^{\mathrm{a}}$, Mariana Coutinho Studart ${ }^{\mathrm{b}}$, \\ Vera Lucia Antunes Chagas ${ }^{b}$, Eloa Pereira Brabo ${ }^{c}$, \\ Leonardo Vieira Neto ${ }^{a, d}$
}

\begin{abstract}
Neuroendocrine tumors (NETs) of cystic duct are extremely rare, accounting for less than $2 \%$ of NET cases. The association of biliary tree NET and multiple endocrine neoplasm type 1 (MEN1) are even more rare. In this report, we described a case of a 65-year-old woman who was referred to our neuroendocrine outpatient clinic to investigate MEN1 after an incidental diagnosis of gastrinoma. Her medical history initiated 7 years earlier with severe peptic disease not responsive to proton pump inhibitor therapy. Endoscopic study revealed erosive antral gastritis, erosive duodenitis, bulbar ulcer and pyloric deformity. During follow-up she presented with abdominal pain, chronic diarrhea and weight loss; an ultrasonography was performed and showed only a cholelithiasis. She underwent a video laparoscopic cholecystectomy and all her symptoms were solved. Histopathological study found a $1.0 \mathrm{~cm}$ well differentiated NET (Ki-67 labeling index $<2 \%$ ) located in cystic duct infiltrating the entire wall and subserosa. The MEN1 investigation revealed a primary hyperparathyroidism with a brown tumor in right iliac bone; the patient was referred to a total parathyroidectomy with autotransplantation. No evidence of pituitary tumor was found. The patient remains asymptomatic 24 months after surgery. To conclude, this case highlights an unusual presentation of a cystic duct primary NET gastrinoma in a MEN1 context.
\end{abstract}

Keywords: Neuroendocrine tumor; Cystic duct; Biliary tree; Multiple endocrine neoplasia type 1; Gastrinoma; Zollinger-Ellison syndrome

Manuscript submitted July 26, 2018, accepted August 14, 2018

aDepartment of Internal Medicine and Endocrine Unit, Medical School and Clementino Fraga Filho University Hospital, Federal University of Rio de Janeiro, Rio de Janeiro, Brazil

bPathology Department, Medical School and Clementino Fraga Filho University Hospital, Federal University of Rio de Janeiro, Rio de Janeiro, Brazil 'Oncology Unit and Neuroendocrine Section, Clementino Fraga Filho University Hospital, Federal University of Rio de Janeiro, Rio de Janeiro, Brazil ${ }^{\mathrm{d} C o r r e s p o n d i n g ~ A u t h o r: ~ L e o n a r d o ~ V i e i r a ~ N e t o, ~ C l e m e n t i n o ~ F r a g a ~ F i l h o ~ U n i-~}$ versity Hospital, Federal University of Rio de Janeiro, Professor Rodolpho Paulo Rocco, 255 Street, 9th Floor, Endocrine Unit, University City, Rio de Janeiro, 21941-913, Brazil. Email: netolv@gmail.com

doi: https://doi.org/10.14740/jocmr3541w

\section{Introduction}

Neuroendocrine tumors (NETs) are neoplasms of variable malignant potential, which arise from the embryonic neural crest cells. The enteropancreatic NET occurs in up to $60 \%$ of multiple endocrine neoplasia type1 (MEN1) patients [1-3].

Extrahepatic biliary NET is an extremely rare malignancy $[4,5]$. They account for $0.2 \%$ to $2 \%$ of all NET of the gastrointestinal tract; and the most common sites include the common biliary duct (CBD), followed by the perihilar region, cystic duct and common hepatic duct (CHD) [4-6]. Rarely the extrahepatic biliary tree NETs are gastrinomas, and there are less than 10 cases associated with MEN1 reported in the literature $[3,7,8]$. They commonly occur in young females and the clinical condition is variable; some cases may be diagnosed as incidental finding post-cholecystectomy $[4,5]$. In general, surgical approach is recommended $[4,5]$.

Our case describes a patient with a cystic duct gastrinoma diagnosed after videolaparoscopic cholecystectomy in a context of MEN1.

\section{Case Report}

A 65-year-old female was referred to our neuroendocrine outpatient clinic for a complete assessment of MEN1. Her clinical history began at the age of 58 with mesogastric pain mainly after fatty food intake, chronic diarrhea and steatorrhea and $4.95 \mathrm{~kg}$ weight loss in that time period.

The patient had 7 years of severe peptic disease not responsive to proton pump inhibitor (PPI) therapy (omeprazole $80 \mathrm{mg} /$ day) and kidney stones. Her family history consisted of a sister who had a diagnosis of hyperparathyroidism. Her physical examination was normal.

A laboratory evaluation for hepatitis, celiac disease, inflammatory bowel disease and intestinal protozoal infections were performed and no abnormality was found.

Initial abdominal ultrasonography (US) was normal but approximately 1 year later a repeated US showed cholelithiasis and a dilated choledochal duct $(0.9 \mathrm{~cm})$. Esophago-gastro-duodenoscopy (EGDS) showed the presence of reflux esophagitis (Los Angeles B), erosive antral gastritis, erosive duodenitis, bulbar ulcer and pyloric deformity (Fig. 1). Colonoscopy showed lymphoid hyperplasia of terminal 


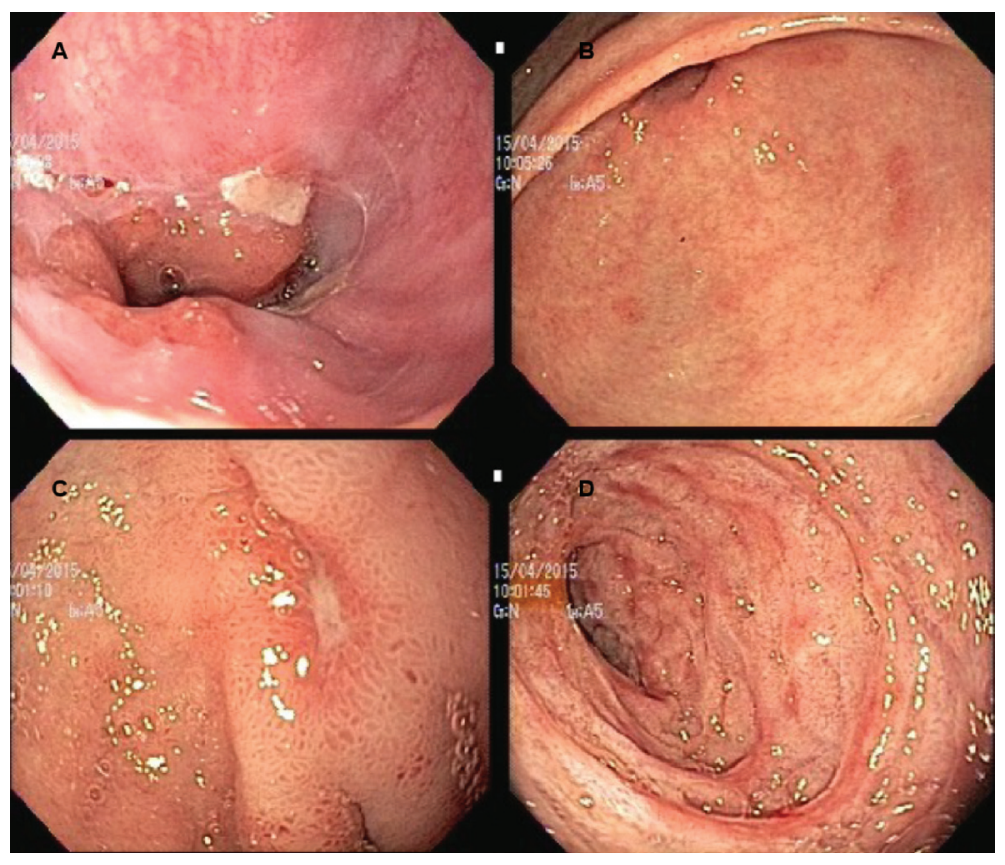

Figure 1. Esophago-gastro-duodenoscopy images. (A) Reflux esophagitis (Los Angeles B). (B) Erosive antral gastritis. (C) Bulbar ulcer. (D) Erosive duodenitis.

ileum. She underwent a videolaparoscopic cholecystectomy and histopathological examination revealed a well differentiated NET grade 1 (Ki-67 labeling index $<2 \%)$ and immunostaining positive for chromogranin $\mathrm{A}(\mathrm{CgA})$ and synaptophysin (Syn) (Fig. 2). The NET was located at the cystic duct, measured $1.0 \mathrm{~cm}$ and infiltrated the entire wall and subserosa. Surgical margins of the cystic duct were free, but exiguous.
No presence of angiolymphatic or perineural invasion was detected.

After surgery the patient has no more abdominal pain or peptic symptoms. The clinical diagnosis of gastrinoma with Zollinger-Ellison Syndrome (ZES) was established and MEN1 screening showed elevated levels of calcium and parathyroid hormone (PTH). No abnormality in prolactin and

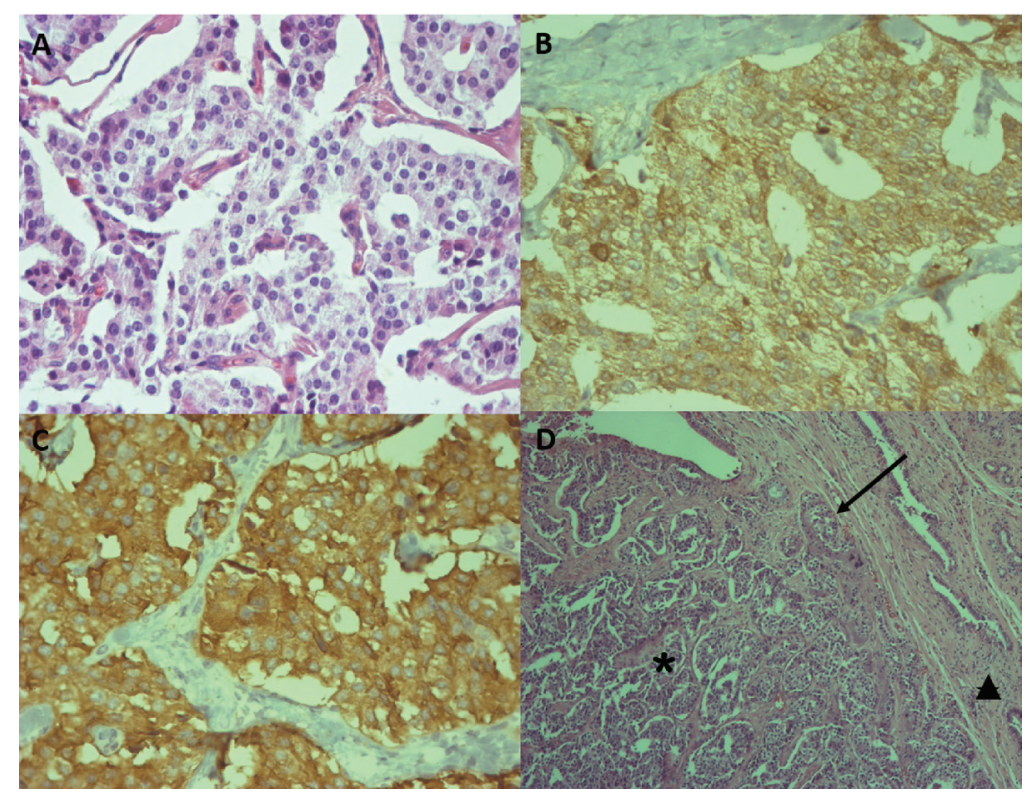

Figure 2. Immunohistopathological analysis of neuroendocrine tumor of cystic duct. (A) Neuroendocrine tumor displaying cells with eosinophilic cytoplasm and rounded and regular nuclei (H\&E, $\times 400)$. (B) Neoplastic cells positive for chromogranin $(\times 400)$. (C) Neoplastic cells positive for synaptophysin $(\times 400)$. (D) Neuroendocrine tumor $\left(^{*}\right)$ occupying the lumen of the cystic duct $(\leftarrow)$ and infiltrating the wall $(\mathbf{\Delta})(\mathrm{H \& E}, \times 100)$. 
Table 1. Post-Operative Laboratory Evaluation

\begin{tabular}{lll}
\hline & Values & Normal range \\
\hline Calcium $(\mathrm{mg} / \mathrm{dL})$ & 11.8 & $8.5-10.5$ \\
Phosphorus $(\mathrm{mg} / \mathrm{dL})$ & 3.0 & $2.5-4.5$ \\
Parathyroid hormone $(\mathrm{pg} / \mathrm{mL})$ & 154 & $12-65$ \\
24 h urine calcium $(\mathrm{mg} / 24 \mathrm{~h})$ & 170 & $112-353$ \\
Prolactin $(\mathrm{ng} / \mathrm{mL})$ & 6.49 & $<20.3$ \\
Insulin growth factor 1 (ng/mL) & 141 & $75-212$ \\
Gastrin (pg/mL) & 10 & $13-115$ \\
Chromogranin A (U/mL) & 101.6 & $\mathrm{Up} \mathrm{to} 100$ \\
5-hydroxyindoleacetic acid $(\mathrm{mg} / 24 \mathrm{~h})$ & 2.7 & $2-9$ \\
\hline
\end{tabular}

insulin-like growth factor 1 (IGF-1) levels were observed (Table 1). The pituitary gland magnetic resonance imaging (MRI) was normal. Postoperative gastrin and $\mathrm{CgA}$ serum levels were normal (Table 1). During 24 months on regular follow-up the patient has not presented diarrhea and gained $19.8 \mathrm{~kg}$. She remains with no peptic symptoms and no PPI therapy. Abdominal computerized tomography (CT) scan had no abnormality. The EGDS was normal 10 months after surgery (Fig. 3). Thus, no adjuvant therapy was indicated. During follow-up, an investigation concerning the patient complaint of a right hip pain revealed a brown tumor in the right femoral trochanter. The bone densitometry also revealed osteoporosis. She was referred to a total parathyroidectomy with autotransplantation. At the time of the last follow-up no pituitary disease was detected.

Verbal and written informed consent was obtained from the patient for publication in this case report.

\section{Discussion}

Gastrinomas are the most common functional enteropancreatic NET and are more frequently localized in the duodenum and less commonly in the pancreas. Approximately $20 \%$ of gastrinomas are associated with MEN1 syndrome [9], and in this context the duodenum is the predominant primary location. Tonelli et al [3] described three patients with MEN1 and ZES presenting with ectopic gastrinomas located in the biliary tree and coexisting duodenal gastrinomas. In two cases the biliary tree gastrinomas were identified during surgery and in one case the diagnosis was made 1 year after the first surgery in a patient with persistent ZES. Another report described a case of a primary hepatic gastrinoma in a patient with MEN1 and ZES [8]. There are two other cases of biliary tree gastrinomas in MEN1 patients and ZES [7]. In our patient a coexisting duodenal gastrinoma could not be found, she remained asymptomatic with normal EGDS and gastrin levels more than 24 months after surgery, also an echo upper endoscopy did not show any submucosal lesion in the duodenum. The patient remains in close follow-up.

To date, we presented the seventh case described in the literature regarding an ectopic gastrinoma in MEN1 patients with ZES. Also, this is the second case to describe a patient with an exclusive biliary tree gastrinoma (duodenum not affected) in a patient with MEN1. Table $2[3,7,8]$ summarizes all seven cases. Longer follow-up is necessary before we can rule out a small duodenal occult lesion.

We have to be aware of certain signs and symptoms that may lead us to suspect of a gastrinoma such as gastroesophageal reflux symptoms, multiple ulcers, ulcers in unusual locations (post-bulbar regions), diarrhea, steatorrhea, weight loss or necessity to use high doses of PPI to control or treat the symptoms/diseases or the inability to control/treat them de-

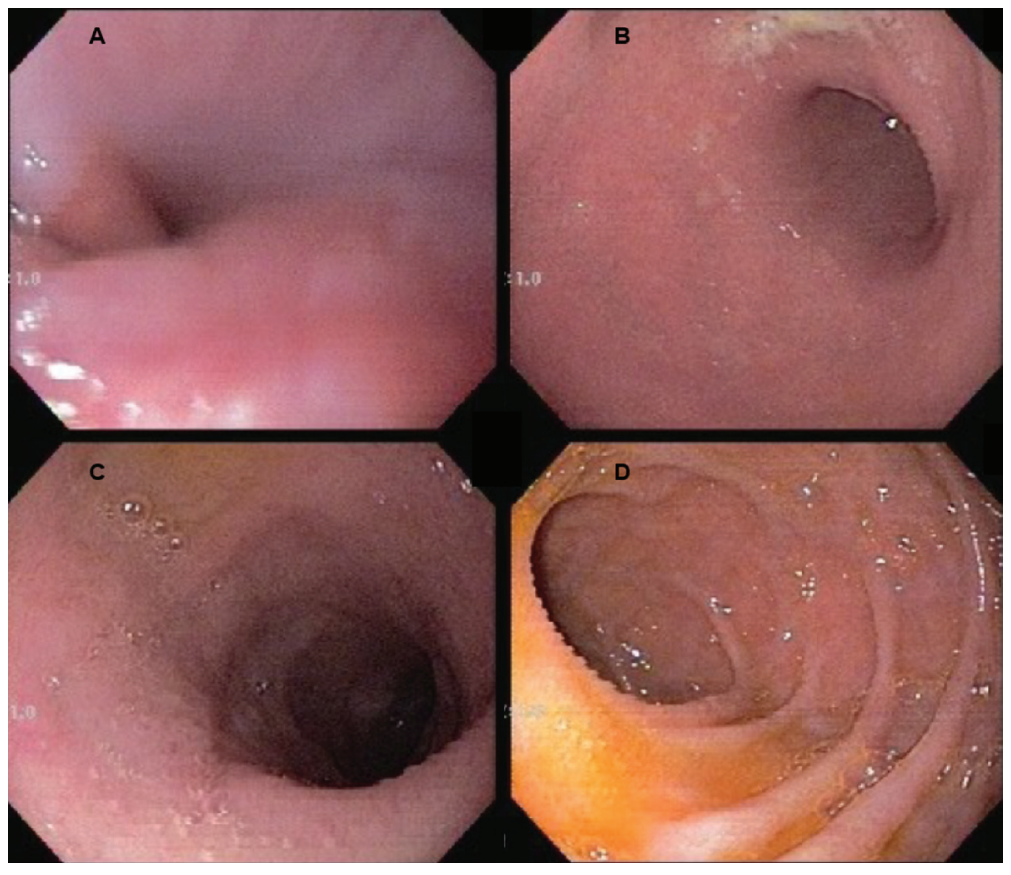

Figure 3. Normal esophago-gastro-duodenoscopy examination 10 months after surgery (A, B, C and D). 


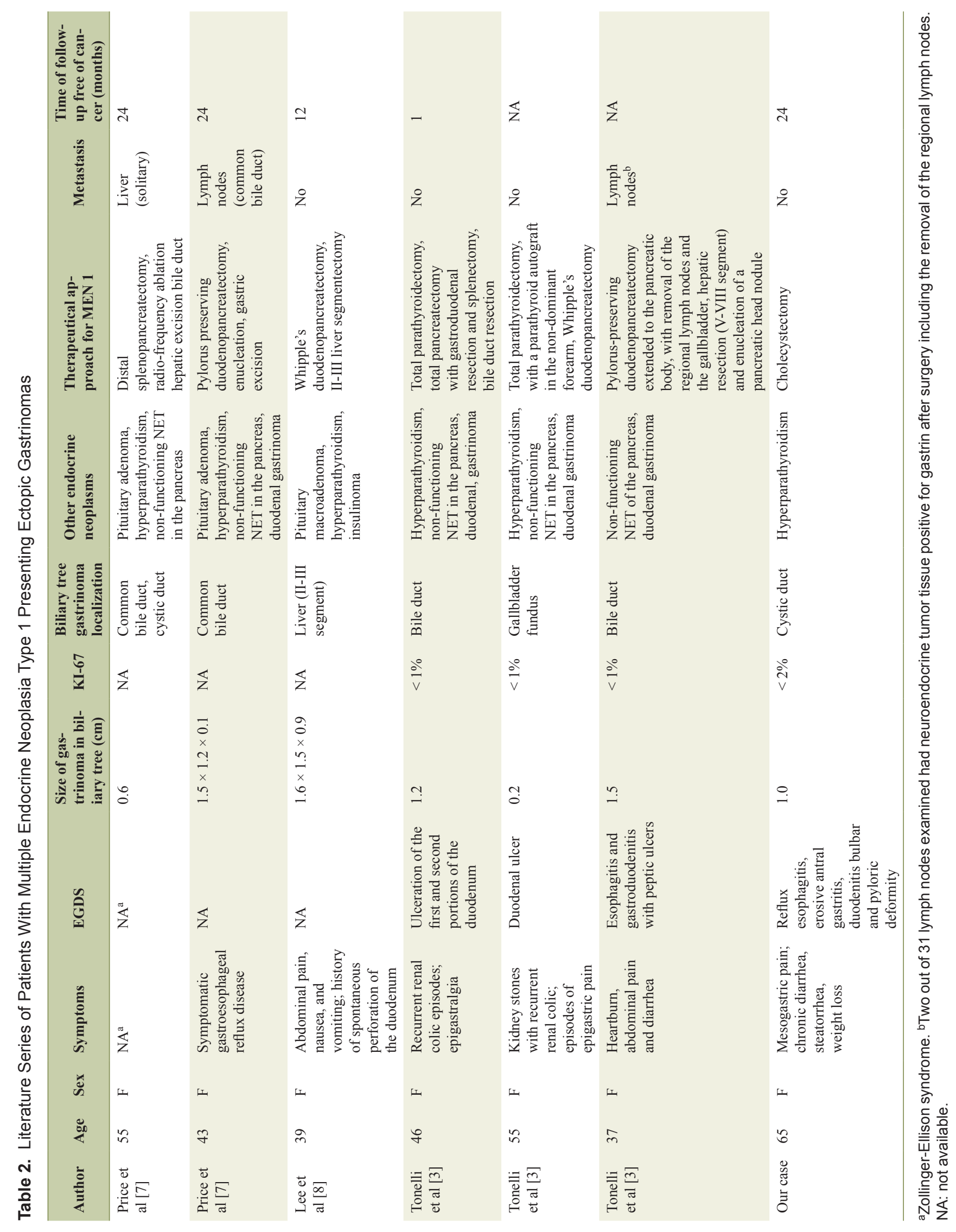


spite high doses of PPI. And whenever faced with a patient with hyperparathyroidism and suggestive clinical features of gastrinoma we have to look for MEN1 syndrome. Although ZES has not been suspected before surgery even in the presence of peptic symptoms, it was possible after surgery.

In the context of ZES in MEN1 patients we must also be aware of extraduodenal primaries mainly during surgical procedures where we need to inspect the biliary tree. An occult extra duodenal gastrinoma may be the cause of surgery failure after duodenopancreatectomy, mainly in cases of ZES symptoms persistence.

Based on these results, we concluded that the patient had a primary NET of cystic duct, a gastrinoma and a primary hyperparathyroidism that may co-exist in patients with MEN1.

\section{Conflict of Interest}

The authors declare that there is no conflict of interest that could be perceived as prejudicing the impartiality of the research reported.

\section{Funding}

This research did not receive any specific grant from any funding agency in the public, commercial or not-for-profit sector.

\section{References}

1. Calender A, Cadiot G, Mignon M. [Multiple endocrine neoplasia type 1: genetic and clinical aspects]. Gastroenterol Clin Biol. 2001;25(4 Suppl):B38-48.

2. Thakker RV, Newey PJ, Walls GV, Bilezikian J, Dralle H, Ebeling PR, Melmed S, et al. Clinical practice guidelines for multiple endocrine neoplasia type 1 (MEN1). J Clin Endocrinol Metab. 2012;97(9):2990-3011.

3. Tonelli F, Giudici F, Fratini G, Brandi ML. Pancreatic endocrine tumors in multiple endocrine neoplasia type 1 syndrome: review of literature. Endocr Pract. 2011;17(Suppl 3):33-40.

4. Michalopoulos N, Papavramidis TS, Karayannopoulou G, Pliakos I, Papavramidis ST, Kanellos I. Neuroendocrine tumors of extrahepatic biliary tract. Pathol Oncol Res. 2014;20(4):765-775.

5. Safwan M, Vij M, Govil S, Rela M. Well-differentiated neuroendocrine tumour of the extrahepatic bile duct: a case report with review of literature. J Gastrointest Cancer. 2016;47(1):93-99.

6. Chamberlain RS, Blumgart LH. Carcinoid tumors of the extrahepatic bile duct. A rare cause of malignant biliary obstruction. Cancer. 1999;86(10):1959-1965.

7. Price TN, Thompson GB, Lewis JT, Lloyd RV, Young WF. Zollinger-Ellison syndrome due to primary gastrinoma of the extrahepatic biliary tree: three case reports and review of literature. Endocr Pract. 2009;15(7):737-749.

8. Lee SR, Choi MC, Ahn KJ. A case of multiple endocrine neoplasia type 1 with primary liver gastrinoma. J Korean Med Sci. 2010;25(6):953-956.

9. Fendrich V, Langer P, Waldmann J, Bartsch DK, Rothmund M. Management of sporadic and multiple endocrine neoplasia type 1 gastrinomas. Br J Surg. 2007;94(11):13311341. 